\title{
Determinants of medical prescriptions for COPD care: an analysis of the EPOCONSUL clinical audit
}

This article was published in the following Dove Press journal: International Journal of COPD

Jose Luis Lopez-

Campos, ${ }^{1,2}$ Bernardino

Alcázar Navarrete, ${ }^{3}$ Joan

B Soriano, ${ }^{4}$ Juan J Soler-

Cataluña, ${ }^{5}$ José Miguel

Rodríguez González-Moro, ${ }^{6}$

Manuel E Fuentes Ferrer, ${ }^{7-9}$

Myriam Calle Rubio $7,8,10$

On behalf of the

EPOCONSUL study group

'Medical-Surgical Unit of Respiratory Diseases, Instituto de Biomedicina de Sevilla, Hospital Universitario Virgen del Rocío, Universidad de Sevilla, Sevilla, Spain; ${ }^{2}$ CIBER of Respiratory Diseases, Instituto de Salud Carlos III, Madrid, Spain; ${ }^{3}$ Pneumology Department, Hospital de Alta Resolución de Loja, Granada, Spain; ${ }^{4}$ Research Institute, Hospital Universitario de la Princesa, Universidad Autónoma de Madrid,

Madrid, Spain; ${ }^{5}$ Pneumology Department, Hospital de Arnau de Villanova-

Lliria, Valencia, Spain; ${ }^{6}$ Pneumology

Department, Hospital Universitario Príncipe de Asturias, Madrid, Spain; ${ }^{7}$ Department of Medicine, Faculty of Medicine, University Complutense of Madrid, Madrid, Spain; ${ }^{8}$ Research Unit, Instituto de Investigación del Hospital Clínico San Carlos, Madrid, Spain; ${ }^{9}$ Clinical Management Unit, Preventive Medicine and Research Institute of Hospital Clínico San Carlos, Madrid, Spain; ${ }^{10}$ Pneumology Department, Hospital Clínico San Carlos, Madrid, Spain

Correspondence: Jose Luis Lopez-Campos Unidad Médico-Quirúrgica de Enfermedades Respiratorias, Instituto de Biomedicina de Sevilla, Hospital Universitario Virgen del Rocío, Universidad de Sevilla, Avenida Manuel Siurot, s/n, 41012 Seville, Spain Email lcampos@separ.es
Purpose: Current COPD management recommendations indicate that pharmacological treatment can be stepped up or down, but there are no recommendations on how to make this adjustment. We aimed to describe pharmacological prescriptions during a routine clinical visit for COPD and study the determinants of changing therapy.

Methods: EPOCONSUL is a Spanish nationwide observational cross-sectional clinical audit with prospective case recruitment including 4,508 COPD patients from outpatient respiratory clinics for a period of 12 months (May 2014-May 2015). Prescription patterns were examined in 4,448 cases and changes analyzed in stepwise backward, binomial, multivariate, logistic regression models.

Results: Patterns of prescription of inhaled therapy groups were no treatment prescribed, 124 $(2.8 \%)$ cases; one or two long-acting bronchodilators (LABDs) alone, 1,502 (34.6\%) cases; LABD with inhaled corticosteroids (ICSs), 389 (8.6\%) cases; and triple therapy cases, 2,428 $(53.9 \%)$ cases. Incorrect prescriptions of inhaled therapies were observed in $261(5.9 \%)$ cases. After the clinical visit was audited, 3,494 (77.5\%) cases did not modify their therapeutic prescription, $307(6.8 \%)$ cases had a step up, $238(5.3 \%)$ cases had a change for a similar scheme, $182(4.1 \%)$ cases had a step down, and 227 (5.1\%) cases had other nonspecified change. Stepping-up strategies were associated with clinical presentation (chronic bronchitis, asthma-like symptoms, and exacerbations), a positive bronchodilator test, and specific inhaled medication groups. Stepping down was associated with lung function impairment, ICS containing regimens, and nonexacerbator phenotype.

Conclusion: The EPOCONSUL study shows a comprehensive evaluation of pharmacological treatments in COPD care, highlighting strengths and weaknesses, to help us understand how physicians use available drugs.

Keywords: COPD, clinical audit, pharmacological prescriptions, quality of care

\section{Introduction}

Several studies have consistently shown that drug prescribed for the treatment of COPD differs markedly from that recommended in current recommendation documents. ${ }^{1,2}$ In brief, the different available studies indicate that there is an overprescription of inhaled corticosteroids (ICSs), an underutilization of long-acting bronchodilators (LABDs), a use of oral treatments not always according to their formal indications, and a drug use in disagreement with different patient types. ${ }^{3-8}$

Despite the valuable information these studies provide, they are frequently based on automated databases that do not allow to understand the determinants of pharmacological prescription in daily clinical practice. Although some previous studies have assessed this aspect, ${ }^{6,7,9,10}$ most of these studies are conducted in primary care and evaluate only partial aspects of drug prescription. Accordingly, there is a need for a 
prospective, comprehensive evaluation on what are the key elements on which physicians base their therapeutic decisions in secondary care.

In this context, clinical audits have emerged as a new tool with potentials for describing the clinical behavior in a determined clinical context, time, and geographical area, with the potential of analyzing the determinants that explain this clinical behavior, and designing a feedback strategy with the final aim to improving health care. ${ }^{11}$ COPD is a common, severe, and disabling condition but a preventable and treatable disease, and it has recently been assessed in clinical audits with the aim to highlight areas of improvement in daily clinical practice. Several recent initiatives have given valuable data on how COPD is delivered to patients in different clinical scenarios. ${ }^{12-14}$

Regarding pharmacological prescription in secondary care outpatients, a recent pilot clinical audit evaluated clinical performance of pulmonologists in COPD outpatients. ${ }^{15}$ This audit highlighted the variability in medical prescriptions for COPD in pulmonologists' outpatient clinics, ${ }^{16}$ showing the patterns of prescriptions and the determinants that led to treatment changes. However, the sample size was limited and the authors suggested that a nationwide analysis would be needed to confirm the results.

EPOCONSUL is a nationwide clinical audit aiming at evaluating clinical care delivered to COPD patients and describing the degree of adjustment to clinical guides in the outpatient secondary care setting. ${ }^{17}$ By using the EPOCONSUL database, we aimed to describe pharmacological prescriptions (inhaled and oral) during a routine clinical visit for COPD, understand the distribution in different patient types, and study the determinants of changing therapy in daily clinical practice. The results of the analysis might help clinical and health care managers to understand medical prescription and improve clinical care in COPD patients.

\section{Methods}

The methodology of EPOCONSUL has been thoroughly reported previously. ${ }^{17}$ Briefly, EPOCONSUL is a clinical audit that evaluates health care for outpatients with COPD in the field of specialized outpatient clinics of pneumology. It is, therefore, an observational study with prospective case recruitment and cross-sectional analysis. The sample was selected from May 2014 to May 2015 from patients seen in an outpatient clinic of the participating centers. The recruitment of patients was prospective. With the idea of having information on the whole year, the inclusion was made in bimonthly periods. At the beginning of each of these bimonthly periods, each researcher included the first 10 patients in the clinic who had an established diagnosis of COPD and who were being followed up by this outpatient clinic. Inclusion criteria required patients to have a confirmed diagnosis of COPD, including being smokers or ex-smokers with an exposure of at least 10 pack-years, $>40$ years old, and presenting with chronic respiratory symptoms suggestive of COPD together with a nonreversible bronchial obstruction by performing a postbronchodilator spirometry with a forced expiratory volume in 1 second $\left(\mathrm{FEV}_{1}\right)$ /forced vital capacity (FVC) ratio $<0.7$. In those cases, where no broncho-reversibility tests were available, it was also accepted as diagnostic criteria to have an $\mathrm{FEV}_{1} / \mathrm{FVC}$ ratio of $<0.7$, together with an $\mathrm{FEV}_{1}$ value of $<80 \%$. The project considered to exclude patients who had a follow-up time of $<1$ year and patients who were already actively participating in another COPD-related research project. All the information during the audit was historical for the data on the clinical performance. However, the information regarding hospital resources was concurrent.

The protocol was approved by the ethics committee of the San Carlos Clinical Hospital (Madrid, Spain, internal code 14/030-E). This approval certified that the present study complied with the ethical principles formulated in the Declaration of Helsinki. In addition, it considered the preservation of the confidentiality of patient data as an important pillar. The protocol was also approved by the local ethics committee of each participating hospital. Currently, research laws in Spain (the Biomedical Research Act of 2007 and the Data Protection Act of 1999) explicitly state that individual consent is not necessary for retrospective evaluations of data obtained from routine clinical care for audit and research purposes, as in our study. For this reason, the signing of written informed consent by the included patients was not required. Likewise, the audited physicians were not informed about the clinical audit in order to preserve the usual clinical practice and the blinding of the clinical performance evaluation. The patient's data were coded, and their confidentiality was conserved in accordance with Spanish laws. The Scientific Committee had the responsibility to guarantee the scientific and methodological precision of the study and the quality control of all the collected data.

For the present study, prescription patterns were analyzed. Inhaled treatment plans were divided into six categories: those patients with no prescriptions of any inhaled medication, treatment with one LABD, treatment with ICS alone, two LABD, LABD-ICS therapies, and triple therapy (longacting muscarinic antagonists [LAMA] + long-acting beta 2 agonists $[\mathrm{LABA}]+\mathrm{ICS})$. Since the efficacy of inhaled drugs 
has been shown to be similar regardless of the administration in single or different inhalers, ${ }^{18-21}$ we considered these groups when prescribed together in one single inhaler or not. Asthma-COPD overlap was defined as in the Spanish National COPD Guideline (GesEPOC). ${ }^{22}$

Incorrect therapeutic schemes were also explored. Since the current Global Initiative for Obstructive Lung Disease (GOLD) 2017 A-D patient type classification is not specific enough to evaluate the correctness of a prescription at the patient level, ${ }^{23}$ we identified incorrect prescriptions as those $\mathrm{B}-\mathrm{D}$ patients not receiving LABD, patients receiving ICS alone, or those with same-class medications in different inhalers.

During the audited clinical visit, treatments that patients were receiving before the visit and changes taken after the visit were noted. Treatment changes were noted according to the following groups: cases with no change in the therapeutic scheme, step-up therapies, changes for a similar therapeutic scheme, and step-down changes. Step-up and -down changes were focused on three aspects: modifying the number or dose of LABD, modifying the number or dose of ICS, modifying the prescription of roflumilast, and other nonspecified changes not specifically recorded.

\section{Statistics}

Statistical computations were performed using IBM SPSS Statistics (IBM Corporation, Armonk, NY, USA). Descriptive analysis was summarized by using the absolute (relative) frequencies of the categories for categorical variables and mean (standard deviation) for numerical ones. The variability was expressed as interhospital range (IHR), expressing the maximal and minimal average value in every participating center. By showing the maximal and minimal average value, information on the variability of the different parameters evaluated by the center was provided. The significance of this variability was explored by the analysis of variance (ANOVA) test or the chi-squared test depending on the nature of the variable.

The description of the inhaled therapeutic groups was referred to the complete cohort; however, the prescription of the oral therapies was referred to the population in each inhaled therapy group. A description of the therapeutic changes was done by showing the percentages of cases stepping-up or stepping-down, with these percentages being referred to both the whole cohort and the number of subjects within each therapeutic option. Factors associated with stepping-up or stepping-down were explored as covariates in a bivariate analysis using unpaired $t$-test or chi-squared test depending on the nature of the variable. These significant associations were entered in a stepwise backward, binomial, multivariate, logistic regression model. Two models were built with step up and step down as the dependent variables. Results were expressed as odds ratio (OR) with 95\% confidence intervals (CIs). Alpha error was set at 0.05 .

\section{Results}

The EPOCONSUL cohort was composed of 4,508 COPD patients. The characteristics of the patients in the cohort have been previously reported. ${ }^{17}$ For the present analysis, 60 cases were excluded due to having inconsistent data regarding pharmacological therapies. Therefore, 4,448 cases formed our population sample (Table 1). The prescription of the different inhaled therapy groups in the cohort is shown in Figure 1 and distributed as follows: no treatment prescribed or recorded, 124 cases $(2.8 \%$; IHR: $0 \%-36.7 \%$; $p<0.001)$; one LABD, 511 cases $(11.5 \%$; IHR: $0 \%-33.3 \% ; p<0.001)$; ICS alone, five cases $(0.1 \%$; IHR: $0 \%-3.2 \% ; p=0.210)$; two LABD, 991 cases $(22.3 \%$; IHR: $8.3 \%-72.6 \% ; p<0.001)$; LABD-ICS, 389 cases (8.6\%; IHR: $0 \%-26.9 \% ; p<0.001)$; and triple therapy, 2,428 cases (53.9\%; IHR: $0 \%-78.7 \%$; $p<0.001)$. Altogether, 1,502 cases (34.6\%; IHR: 13.3\%-100\%; $p<0.001$ ) received LABD therapy (one or two LABD) without ICS and 2,822 cases (62.6\%; IHR: 9.5\%-85.0\%; $p<0.001)$ received any form of ICS. Interestingly, $36(0.8 \%$ in the complete cohort; $9.3 \%$ in those receiving LABD-ICS therapy) cases were receiving a combination of an LAMA and an ICS, 107 (2.4\% in the complete cohort; 4.4\% in those receiving triple therapy) cases were receiving triple therapy with all the three drugs in different inhalers, and 332 (7.5\% in the complete cohort; $33.5 \%$ in those receiving double bronchodilator therapy) cases were receiving two bronchodilators in different inhalers.

Table I Demographic and clinical characteristics of COPD participants

\begin{tabular}{llll}
\hline Characteristics & Average & IHR & p-value \\
\hline Gender (male) & $3,823(85.9)$ & $60.0-100$ & $<0.00$ I \\
Age (years) & $69.7(9.7)$ & $63.0-75.4$ & $<0.00$ I \\
Active smokers (n) & $1,029(23.1)$ & $6.5-38.1$ & $<0.00$ I \\
Tobacco exposure (pack-years) & $56.1(33.7)$ & $28.3-106.3$ & $<0.00$ I \\
Body mass index (kg/m²) & $28.0(5.4)$ & $25.2-38.5$ & $<0.00$ I \\
Comorbidities (Charlson) & $2.9(2.1)$ & $1.7-4.7$ & $<0.00$ I \\
FVC (\%) & $77.4(20.9)$ & $49.0-117$ & $<0.00$ I \\
FEV, (\%) & $54.0(18.5)$ & $36.0-86.0$ & $<0.00$ I \\
FEV, reversibility (\%) & $9.7(9.5)$ & $3.1-15.4$ & $<0.00$ I \\
FEV, IFVC (\%) & $52.3(11.7)$ & $65-47.9$ & $<0.00$ I \\
\hline
\end{tabular}

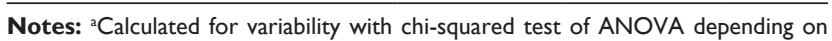
the nature of the variable. Values are expressed as mean (standard deviation) or absolute (relative) frequencies according to the nature of the variable.

Abbreviations: ANOVA, analysis of variance; $\mathrm{FEV}_{1}$, forced expiratory volume in I second; FVC, forced vital capacity; IHR, interhospital range. 


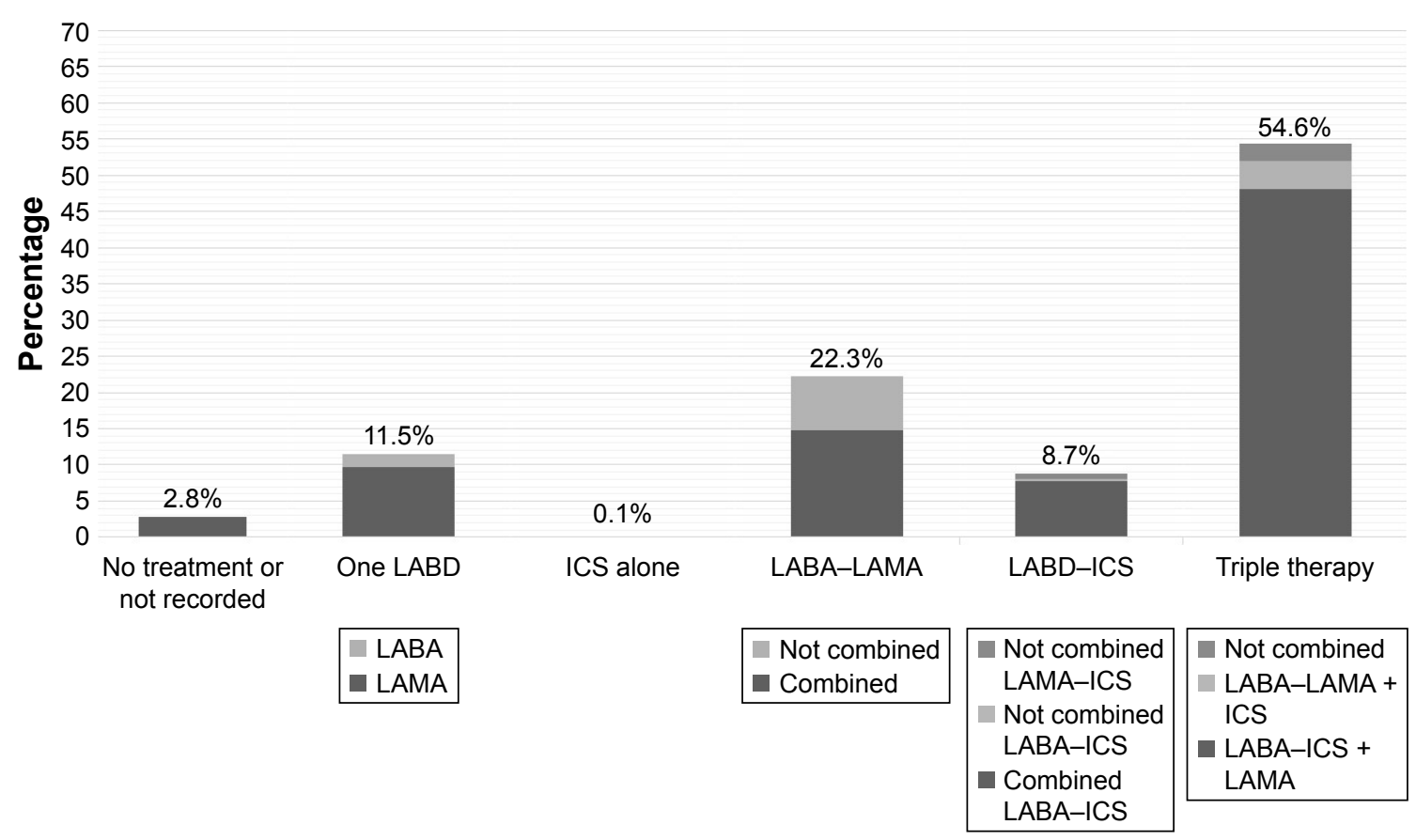

Figure I Distribution of inhaled treatments in the EPOCONSUL cohort.

Note: Percentages refer to the complete cohort.

Abbreviations: ICS, inhaled corticosteroid; LABA, long-acting beta 2 agonists; LABD, long-acting bronchodilator; LAMA, long-acting muscarinic antagonists.

Incorrect prescriptions of inhaled therapies were observed in 261 cases $(5.9 \%$; IHR: $0 \%-55.0 \% ; p<0.001)$ : 25 cases (0.6\%; IHR: $0 \%-14.3 \% ; p<0.001)$ due to not receiving LABD in GOLD B-D patients, 5 cases (0.1; IHR: 0\%-3.2\%; $p<0.001)$ due to receiving ICS alone, and 231 cases $(5.2 \%$; IHR: $0 \%-55.0 \% ; p<0.001$ ) for receiving duplicate therapies.
The prescription of oral treatments is shown in Figure 2 and was distributed as follows (percentages referred to the complete cohort): roflumilast 383 (8.6\%; IHR: $0 \%-31.0 \%$; $p<0.001)$, methylxanthines $282(6.3 \%$; IHR: $0 \%-23.2 \%$; $p<0.001)$, mucolytics $277(6.2 \%$; IHR: $0 \%-31.0 \% ; p<0.001)$, and antibiotics 174 (3.9\%; IHR: $0 \%-20.0 \%$; $p<0.001)$.

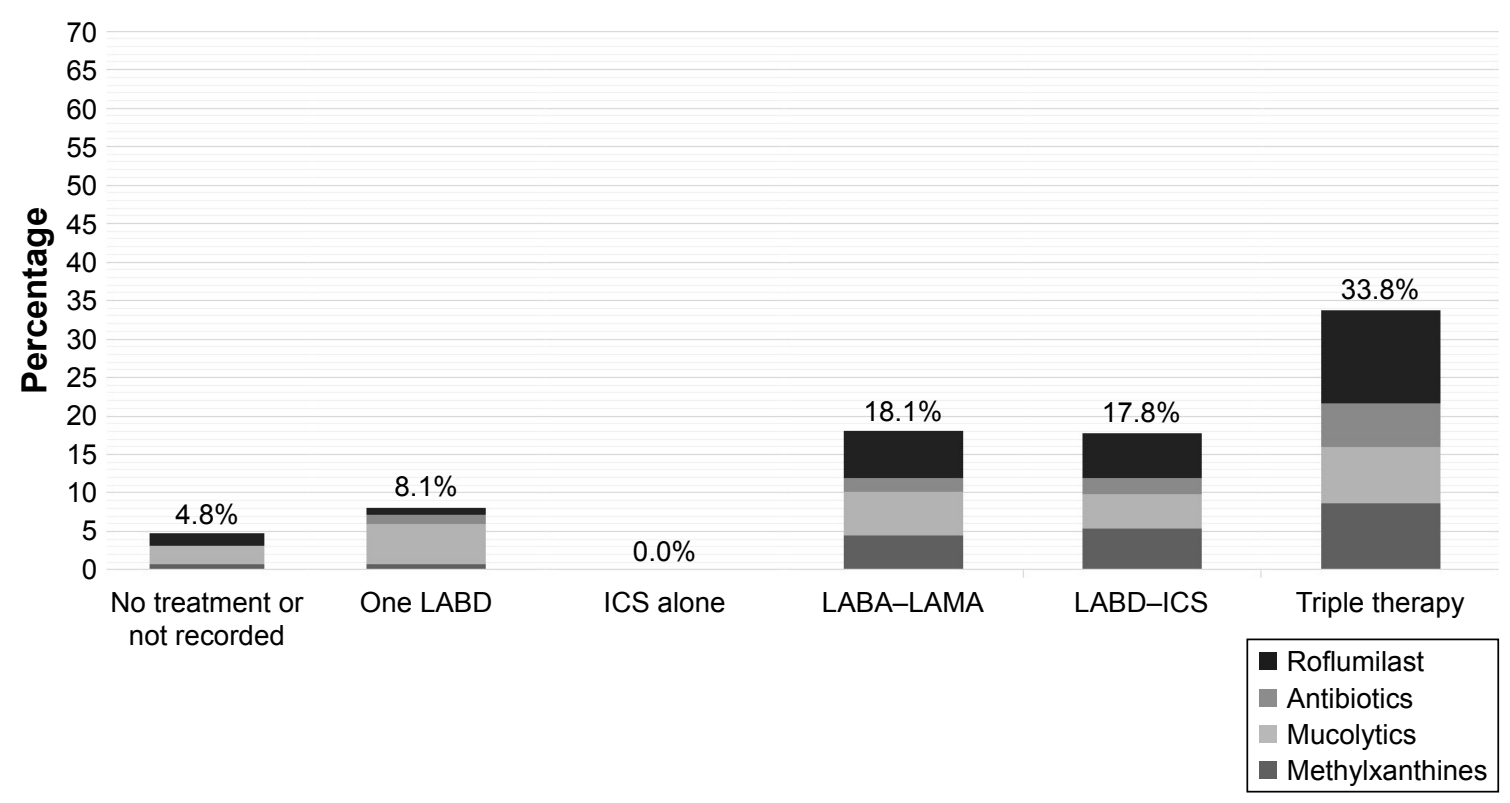

Figure 2 Distribution of oral treatments in the EPOCONSUL cohort.

Note: Percentages refer to the number of patients in each inhaled treatment group.

Abbreviations: ICS, inhaled corticosteroid; LABA, long-acting beta 2 agonists; LABD, long-acting bronchodilator; LAMA, long-acting muscarinic antagonists. 
The distribution of oral therapies according to the inhaled therapy groups is summarized in Figure 2. There was some overlap in the prescription of oral therapies, but this was $<1 \%$ in all patient types, inhaled medication groups, and oral combinations (data not shown).

GOLD patient types were available in 2,613 cases: 681 (15.3\%) GOLD A, 782 (17.7\%) GOLD B, 256 (5.7\%) GOLD C, and 894 (20.0\%) GOLD D. The distribution of inhaled and oral therapies according to GOLD 2017 A-D patient groups is summarized in Figures 3 and 4. Triple therapy was the leading treatment in all GOLD 2017 patient types, followed by double bronchodilator therapy. In GOLD A patients, single bronchodilation and double bronchodilation were close and not far from triple therapies. In the rest of the GOLD 2017 patient types, there was a progressive increase in triple therapy and a progressive decrease in double bronchodilation. Regarding oral therapies, mucolytics were more frequently used in patients with a lower intensity of inhaled therapies, whereas usage of roflumilast increased in more severe cases.

Treatment changes during the audited visit are summarized in Table 2. After the clinical visit audited, 3,494 cases (77.5\%; IHR: $3.3 \%-98.4 \% ; p<0.001$ ) did not modify their therapeutic prescription, 307 cases $(6.8 \%$; IHR: $0 \%-66.7 \%$; $p<0.001)$ had a step up, 238 cases $(5.3 \%$; IHR: $0 \%-26.7 \%$; $p<0.001)$ had a change for a similar scheme, 182 cases (4.1\%; IHR: $0 \%-25.0 \% ; p<0.001)$ had a step down, and 227 cases $(5.1 \%$; IHR: $0 \%-25.0 \% ; p<0.001)$ had other nonspecified change.

Bivariate associations of clinical variables with step up or step down of therapy are shown in Tables S1 and $\underline{\mathrm{S}}$, respectively. The multivariate analysis for stepping up is presented in Table 3. Clinical presentation, a positive response in the bronchodilator test, and previous triple therapy were significantly associated with stepping up. The multivariate analysis for stepping down is presented in Table 4. Exacerbations, previous treatment with LABD-ICS, and referral from secondary care were associated with stepping down. Interestingly, lung function was not found to be significantly associated.

\section{Discussion}

Ours is the first nationwide clinical audit performed in Spain in specialized pulmonary outpatient clinics evaluating patterns of pharmacological prescription in COPD. The results of our analysis show that triple therapy continues being the
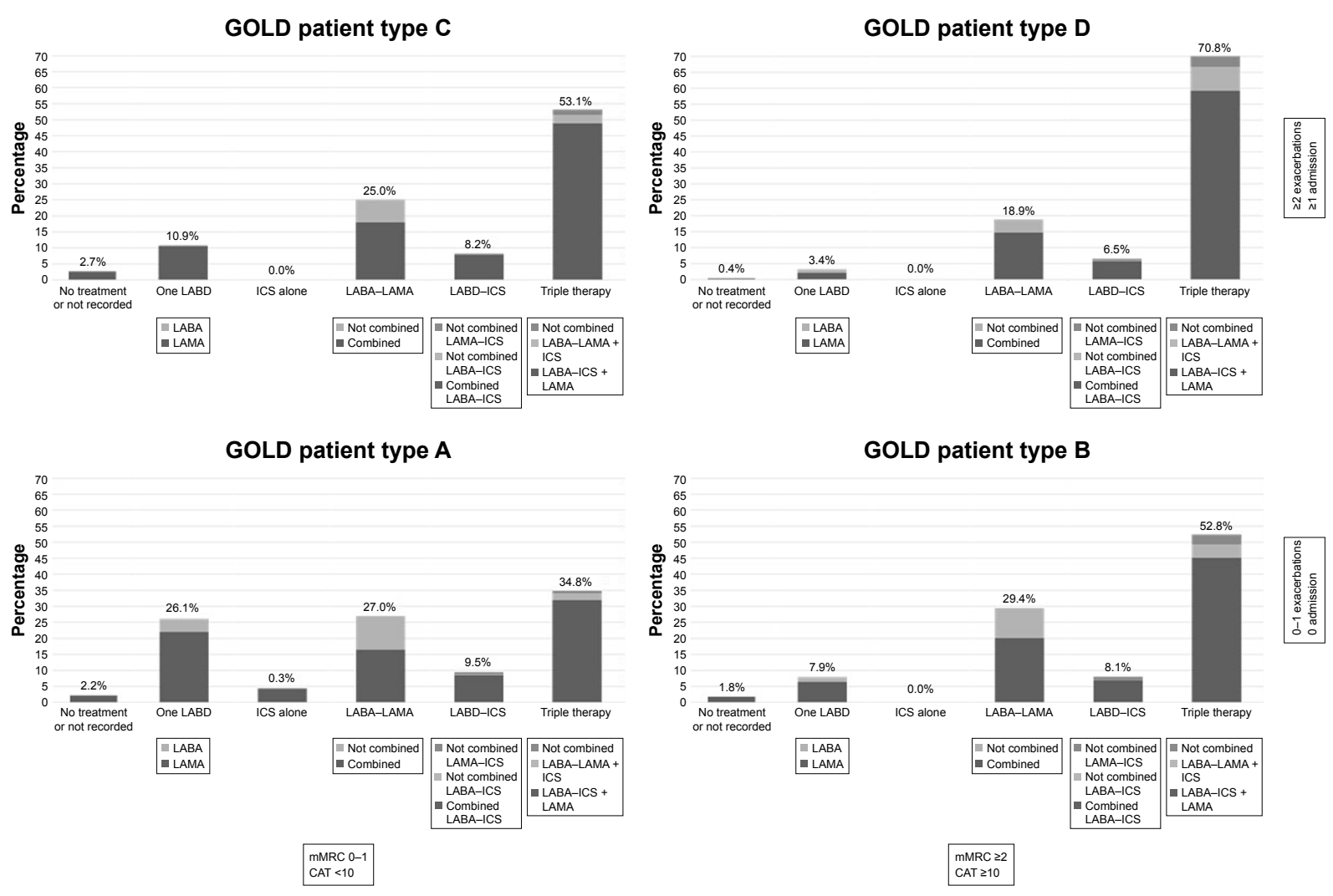

Figure 3 Distribution of inhaled treatments in the EPOCONSUL cohort according to GOLD 2017 patient types A-D.

Note: Percentages refer to the complete cohort.

Abbreviations: CAT, COPD Assessment Test; GOLD, Global Initiative for Obstructive Lung Disease; ICS, inhaled corticosteroid; LABA, long-acting beta 2 agonists; LABD, long-acting bronchodilator; LAMA, long-acting muscarinic antagonists; mMRC, modified Medical Research Council scale. 

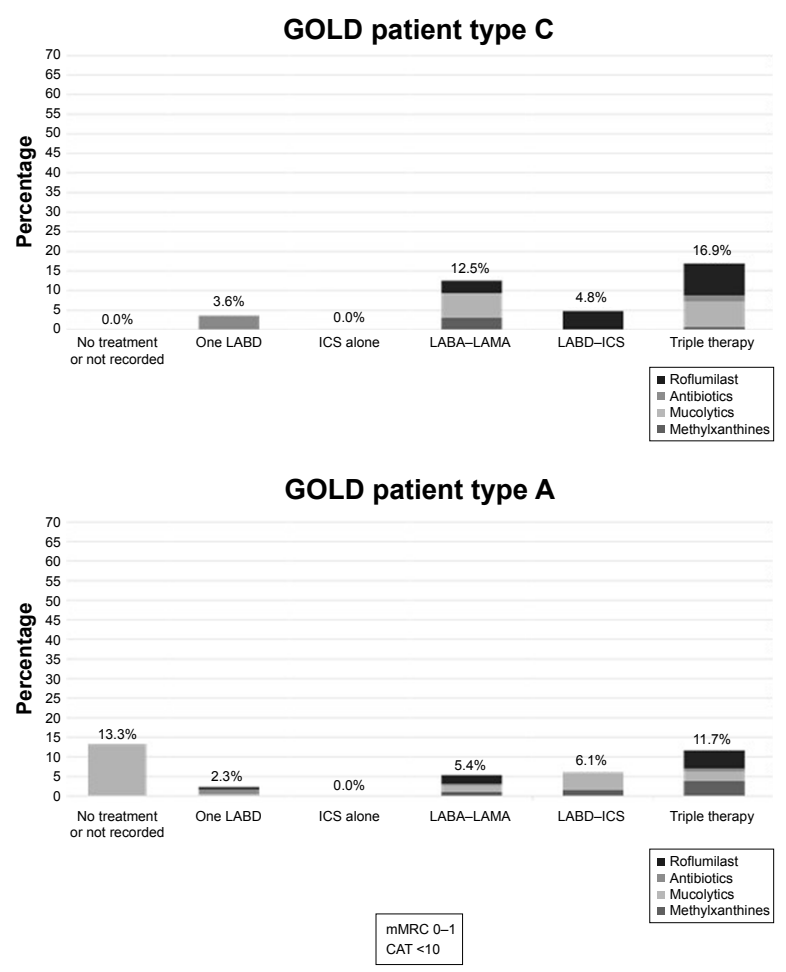

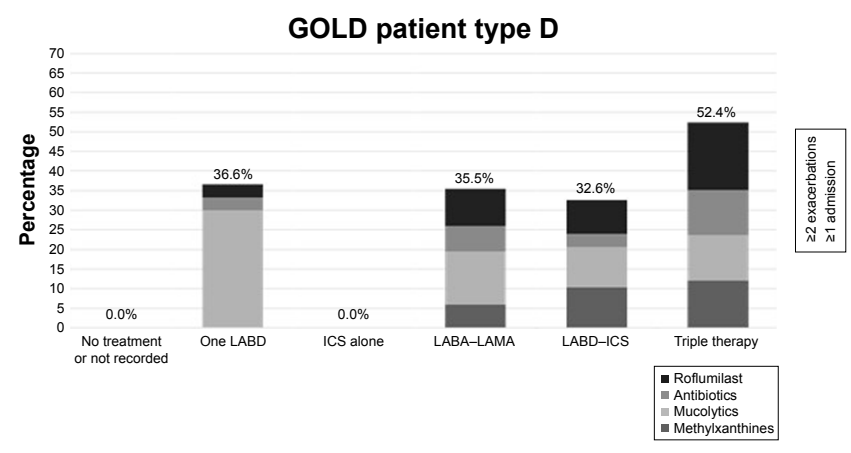

GOLD patient type B

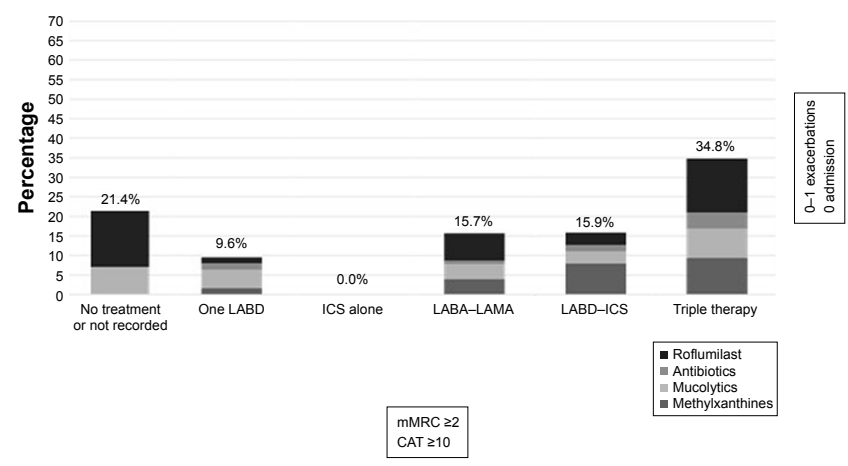

Figure 4 Distribution of oral therapies in the EPOCONSUL cohort according patient groups by GOLD 2017 patient types A-D. Note: Percentages refer to the number of patients in each treatment.

Abbreviations: CAT, COPD Assessment Test; GOLD, Global Initiative for Obstructive Lung Disease; ICS, inhaled corticosteroid; LABA, long-acting beta 2 agonists; LABD, long-acting bronchodilator; LAMA, long-acting muscarinic antagonistsm; mMRC, modified Medical Research Council scale.

most frequently prescribed pattern of medication and that the majority of prescribers do not modify therapeutic regimes in COPD patients after a routine clinical visit.

Clinical audits are complex processes framed in the concept of continuous improvement of the quality of care. These processes seek to improve patient care and its results through cyclical clinical practice evaluation strategies and results compared with recognized standards, subsequently completed through a process of implementing improvements. ${ }^{24}$ According to current understanding, it is expected that health care professionals are able to receive comments on the performance of their usual practice. Although it might seem intuitive that a professional would be prone to modify their daily activities in the light of an evaluation of their quality of care, the real relevance of these changes may not have a great impact on clinical outcomes. ${ }^{25}$ In this sense, one of the great remnants of clinical audits refers to the maintenance over time of this improvement achieved in clinical performance. From this idea, there is a need to establish continuous improvement strategies complemented with feedback that allow the establishment of clinical implementation programs. ${ }^{26}$ Until now, the evaluation of clinical performance in COPD had focused on the hospitalized patient due to an exacerbation of the disease, probably because it is a potentially serious situation with important clinical repercussions for the patient and the health system. However, the situation in outpatient clinics has received much less attention. ${ }^{15}$ Consequently, in the present study, the objective of the work was to advance in the assessment of quality assistance in the field of specialized external care and during a typical follow-up clinical visit.

The main strengths of our study are a nationwide coverage and a comprehensive, systematic evaluation of clinically relevant parameters together with resources and organizational aspects of clinical care. However, several methodological considerations must be observed in order to interpret our results correctly. In the first place, it is important to keep in mind that the clinical guidelines summarize the main norms for the diagnosis and treatment of a process. However, these are general recommendations that are not always based on evidence and do not always conform to all possible clinical presentations of the diseases. Therefore, it is usually common to find some kind of deviation from the recommendations in actual daily clinical practice. As a note, the degree of deviation from this general rule has not been quantified. Second, it is necessary to remember that a clinical audit evaluates the clinical information that a health personnel records in the clinical record. Therefore, an audit cannot identify measures carried out and that are not recorded in the clinical record. A clear example of this 
Table 2 Description of treatment changes during the audited visit

\begin{tabular}{|c|c|c|c|c|c|c|c|}
\hline \multirow[t]{2}{*}{ Basal treatment } & \multirow{2}{*}{$\begin{array}{l}\text { No change } \\
\left.\text { n (\%; }{ }^{\mathrm{b}}\right)\end{array}$} & \multicolumn{2}{|l|}{ Step up } & \multirow{2}{*}{$\begin{array}{l}\text { Similar } \\
\left.\text { n (\%, }{ }^{a} \%\right)\end{array}$} & \multicolumn{2}{|l|}{ Step down } & \multirow{2}{*}{$\begin{array}{l}\text { Others: not } \\
\text { specified } \\
\mathrm{n}\left(\%^{\mathrm{a} ;} \% \%^{\mathrm{b}}\right) \\
\end{array}$} \\
\hline & & Change & n (\%;a \%b) & & Change & n (\%a; \% $\left.{ }^{\mathrm{b}}\right)$ & \\
\hline \multirow{3}{*}{$(n=124)^{c}$} & $88(71.0 ; 2.0)$ & Increase ICS & $2(1.6 ; 0.04)$ & 0 & Decrease ICS & $3(2.4 ; 0.1)$ & $6(4.8 ; 0.1)$ \\
\hline & & Increase BD & $19(15.3 ; 0.4)$ & & Decrease BD & $5(4.0 ; 0.1)$ & \\
\hline & & Add roflumilast & I $(0.8 ; 0.02)$ & & $\begin{array}{l}\text { Discontinue } \\
\text { roflumilast }\end{array}$ & 0 & \\
\hline \multirow[t]{3}{*}{ One LABD $(n=511)$} & 430 (84.1; 9.7) & Increase ICS & $14(2.7 ; 0.3)$ & II $(2.2 ; 0.2)$ & Decrease ICS & 0 & $2 I(4.1 ; 0.5)$ \\
\hline & & Increase BD & $27(5.3 ; 0.6)$ & & Decrease BD & $8(1.6 ; 0.2)$ & \\
\hline & & Add roflumilast & 0 & & $\begin{array}{l}\text { Discontinue } \\
\text { roflumilast }\end{array}$ & 0 & \\
\hline \multirow[t]{3}{*}{ ICS alone $(n=5)$} & $3(60.0 ; 0.1)$ & Increase ICS & I (20.0; 0.02) & 0 & Decrease ICS & 0 & I $(20.0 ; 0.02)$ \\
\hline & & Increase BD & 0 & & Decrease BD & 0 & \\
\hline & & Add roflumilast & 0 & & $\begin{array}{l}\text { Discontinue } \\
\text { roflumilast }\end{array}$ & 0 & \\
\hline \multirow[t]{3}{*}{ Two LABD $(n=991)$} & 744 (75.I; 16.7) & Increase ICS & $30(3.0 ; 0.7)$ & 80 (8.I; I.8) & Decrease ICS & 0 & $52(5.2 ; 1.2)$ \\
\hline & & Increase BD & 60 (6.I; I.3) & & Decrease BD & $2 \mathrm{I}(2.1 ; 0.5)$ & \\
\hline & & Add roflumilast & $4(0.4 ; 0.1)$ & & $\begin{array}{l}\text { Discontinue } \\
\text { roflumilast }\end{array}$ & 0 & \\
\hline \multirow[t]{3}{*}{ LABD-ICS ( $n=389)$} & $284(73.0 ; 6.3)$ & Increase ICS & $8(2.1 ; 0.2)$ & $13(3.3 ; 0.3)$ & Decrease ICS & $15(3.9 ; 0.3)$ & $17(4.4 ; 0.4)$ \\
\hline & & Increase BD & $35(9.0 ; 0.8)$ & & Decrease BD & $14(3.6 ; 0.3)$ & \\
\hline & & Add roflumilast & $2(0.5 ; 0.04)$ & & $\begin{array}{l}\text { Discontinue } \\
\text { roflumilast }\end{array}$ & I $(0.3 ; 0.02)$ & \\
\hline Triple therapy & I,945 (80.I; 43.I) & Increase ICS & $29(1.2 ; 0.6)$ & I $34(5.5 ; 3.0)$ & Decrease ICS & $72(3.0 ; 1.6)$ & I $30(5.4 ; 2.9)$ \\
\hline \multirow[t]{2}{*}{$(n=2,428)$} & & Increase BD & $54(2.2 ; 1.2)$ & & Decrease BD & $31(1.3 ; 0.7)$ & \\
\hline & & Add roflumilast & $21(0.9 ; 0.5)$ & & $\begin{array}{l}\text { Discontinue } \\
\text { roflumilast }\end{array}$ & $12(0.5 ; 0.3)$ & \\
\hline \multirow[t]{3}{*}{ Total $(n=4,448)$} & 3,494 (78.6) & Increase ICS & $84(1.9)$ & $238(5.4)$ & Decrease ICS & $90(2.0)$ & $227(5.1)$ \\
\hline & & Increase BD & $195(4.4)$ & & Decrease BD & $79(1.8)$ & \\
\hline & & Add roflumilast & $28(0.6)$ & & $\begin{array}{l}\text { Discontinue } \\
\text { roflumilast }\end{array}$ & $13(0.3)$ & \\
\hline
\end{tabular}

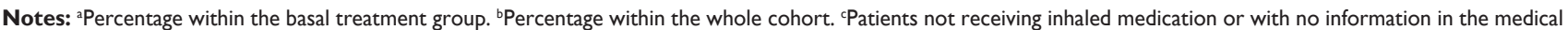
record. An increase reflects an augment in the number or the dose of the drugs. A decrease denotes the decrement in the number or the dose of the drugs.

Abbreviations: BD, bronchodilators; ICS, inhaled corticosteroid; LABD, long-acting bronchodilator.

Table 3 Multivariate analysis with factors associated with stepping up

\begin{tabular}{|c|c|c|c|c|}
\hline \multirow[t]{2}{*}{ Factors } & \multicolumn{2}{|c|}{ Crude } & \multicolumn{2}{|c|}{ Adjusted } \\
\hline & OR & $95 \% \mathrm{Cl}$ & OR & $95 \% \mathrm{Cl}$ \\
\hline Chronic bronchitis & 1.298 & $1.029-1.638$ & 1.315 & $0.995-1.635$ \\
\hline Asthma-like symptoms & 1.479 & $|.157-1.89|$ & 1.315 & $1.010-1.712$ \\
\hline Positive BDT & 2.397 & $1.598-3.596$ & 2.119 & $1.393-3.224$ \\
\hline No inhaled treatment & 3.057 & $1.899-4.921$ & 1.938 & $1.182-3.175$ \\
\hline Triple therapy & 0.401 & $0.3|4-0.5| I$ & 0.370 & $0.285-0.479$ \\
\hline Phenotype: ACO & 1.823 & $1.256-2.647$ & 1.900 & $1.265-2.854$ \\
\hline Phenotype: frequent exacerbator with chronic bronchitis & 1.557 & $1.120-2.164$ & 2.148 & I.498-3.082 \\
\hline Time since previous visit (months) & 1.000 & $1.000-1.001$ & 1.000 & $1.000-1.001$ \\
\hline
\end{tabular}

Abbreviations: $\mathrm{ACO}$, asthma and COPD overlap; $\mathrm{BDT}$, bronchodilator test; $\mathrm{Cl}$, confidence interval; OR, odds ratio.

Table 4 Multivariate analysis with factors associated with stepping down

\begin{tabular}{|c|c|c|c|c|}
\hline \multirow[t]{2}{*}{ Factors } & \multicolumn{2}{|c|}{ Crude } & \multicolumn{2}{|c|}{ Adjusted } \\
\hline & OR & $95 \% \mathrm{Cl}$ & $\overline{\text { OR }}$ & $95 \% \mathrm{Cl}$ \\
\hline Latest available spirometry: $\mathrm{FEV}_{1}(\%)$ & 1.008 & $0.974-1.043$ & 1.025 & $1.010-1.040$ \\
\hline Current spirometry: FVC $<80 \%$ & 1.765 & $1.150-2.710$ & 2.307 & I.193-4.463 \\
\hline ICS-LABD treatment & 2.148 & $\mathrm{I} .43 \mathrm{I}-3.224$ & 12.467 & $5.262-29.538$ \\
\hline Triple inhaled therapy & 1.449 & $1.066-1.970$ & 6.546 & $2.983-14.368$ \\
\hline Phenotype: nonexacerbator & 2.110 & $1.539-2.894$ & 2.571 & $1.50 \mathrm{I}-4.403$ \\
\hline COPD-dedicated outpatient clinic & 1.585 & $1.151-2.183$ & 1.701 & $0.967-2.994$ \\
\hline
\end{tabular}

Abbreviations: $\mathrm{Cl}$, confidence interval; $\mathrm{FEV}$, forced expiratory volume in I second; FVC, forced vital capacity; ICS, inhaled corticosteroid; LABD, long-acting bronchodilator; OR, odds ratio. 
situation could be an evaluation of the inhalation technique that has been performed, but it has not been noted. In this regard, it is important to highlight the need to record all clinical actions with the goal that any health professional has all the relevant information available in the medical record. Third, this audit has had a cross-sectional analysis without evaluating the long-term clinical data. These data will undoubtedly serve as a basis for authors of the future audits to know the points on which to act and to study their long-term clinical impact. Likewise, the prospective impact of the adherence of the guide on the results should be another aspect of future evaluation in terms of rates of exacerbations and survival. In $2.8 \%$ of cases, there was no information on maintenance inhaled therapies. This finding has been previously reported, but with a considerable difference. A recent analysis of the medical records of 3,376 patients from general practice in Denmark revealed that $74.4 \%$ of them did not receive any maintenance inhaled medication even after spirometric confirmation of COPD. ${ }^{27}$ In the UK, $28 \%$ of 20,154 patients, whose medical records were analyzed, in one study ${ }^{6}$ and $20 \%$ of 29,815 patients in another study ${ }^{7}$ received no initial pharmacological treatment. In Sweden, this figure was far below $10 \%$ in secondary care. ${ }^{3}$ In the US, it has been reported that $55 \%$ of such patients did not receive inhaled maintenance therapy. ${ }^{28}$ The reasons for this underprescription of maintenance inhaled therapies in COPD patients fall outside the scope of the present study and would require an ad hoc investigation, but could be partially explained by the type of center and the type of outpatient clinic available in these centers evaluating patients with specific characteristics.

Triple therapy keeps being the most prescribed medication even in A and B COPD patient types. Previous studies have highlighted the overuse of ICS and, in particular, triple therapy in COPD. ${ }^{4,5,29}$ Although still high, the proportion of COPD patients with ICS has not been greatly reduced with previous studies reporting ICS use in $\sim 60 \%{ }^{30}$ compared to $62.6 \%$ in our cohort. Indeed, it has been reported that only half of patients receiving ICS are doing this correctly prescribed. ${ }^{31}$ Interestingly, the overprescription of triple therapy has been described in all clinical settings, primary and secondary care, different countries, and health systems. In our view, there are two reasons why this might be happening: 1) either we all do it wrongly in all countries and settings or 2) the guideline recommendations do not capture the complexity of the COPD patients, and there are other variables beyond lung function, symptoms, and exacerbations that influence clinicians in their medical decisions.
Unfortunately, we do not have studies that can differentiate these two aspects of this controversy. Of note, one significant association with stepping down was the use of LABD-ICS, but not triple therapy, which might reflect a change in the clinical behavior of clinicians. In this regard, the variables associated with stepping up could reflect a trend toward a more personalized medicine in COPD in secondary care.

Duplicate therapies were the most frequently found error in inhaled medication prescription. In the present study, we were able to detect duplicated medications, ie, same-class repeats (eg, LABA-LAMA + ICS-LABA, LABA-LAMA + LABA, or LABA-ICS + ICS). Fortunately, the implementation of electronic prescription in Spain will probably help clinicians to correct all these prescriptions. ${ }^{32}$

After the clinical visit audited, 3,494 (77.5\%) cases did not modify their therapeutic prescription. This result has been reported previously for our country. In a recent pilot clinical audit carried out in Spain, 64.8\% cases saw no change in pharmacological treatment. ${ }^{16}$ The high number of cases in which no drug prescribing modifications are carried out is another interesting debate. These are probably well-controlled patients with no exacerbations and few symptoms, and accordingly, we need to establish whether, when, and how in these cases a step down could be tried. ${ }^{33}$ Although current recommendation documents suggest that stepping down can now be considered, currently there is no universally accepted consensus on how to perform this at the patient level.

\section{Conclusion}

Ours is the first nationwide clinical audit performed in specialized pulmonary outpatient clinics evaluating pharmacological prescriptions in COPD. The results of our analysis show that the majority of chest physicians do not modify COPD therapeutic regimes after a routine clinical visit. Triple therapy in different inhalers continues being the most frequently prescribed medication pattern. The study highlights determinants of medical prescription in COPD, which require further research.

\section{Acknowledgments}

The authors of the present work want to show their sincere gratitude to all the researchers of the EPOCONSUL study for the extraordinary and tireless field work (a list of the EPOCONSUL researchers is available in the Supplementary materials). This study has been promoted and sponsored by the Spanish Society of Pneumology and Thoracic Surgery (SEPAR). The authors thank Boehringer Ingelheim for its 
financial support to carry out the study. The financing entities did not participate in the design of the study, data collection, analysis, publication, or preparation of this manuscript.

\section{Disclosure}

JLLC has received honoraria for lecturing, scientific advice, participation in clinical studies, and writing publications for (alphabetical order) Almirall, AstraZeneca, Bayer, Boehringer Ingelheim, Cantabria Pharma, Chiesi, Esteve, Faes, Ferrer, Gebro, GlaxoSmithKline, Grifols, Menarini, MSD, Novartis, Pfizer, Rovi, Teva, and Takeda. The authors report no other conflicts of interest in this work.

\section{References}

1. Vogelmeier CF, Criner GJ, Martinez FJ, et al. Global strategy for the diagnosis, management, and prevention of chronic obstructive lung disease 2017 report: GOLD executive summary. Am J Respir Crit Care Med. 2017;195(5):557-582.

2. Miravitlles M, Soler-Cataluna JJ, Calle M, et al. Spanish guidelines for management of chronic obstructive pulmonary disease (GesEPOC) 2017. Pharmacological treatment of stable phase. Arch Bronconeumol. 2017;53(6):324-335.

3. Sundh J, Janson C, Johansson G, et al. Characterization of secondary care for COPD in Sweden. Eur Clin Respir J. 2017;4(1):1270079.

4. Simeone JC, Luthra R, Kaila S, et al. Initiation of triple therapy maintenance treatment among patients with COPD in the US. Int J Chron Obstruct Pulmon Dis. 2017;12:73-83.

5. Mapel D, Laliberte F, Roberts MH, et al. A retrospective study to assess clinical characteristics and time to initiation of open-triple therapy among patients with chronic obstructive pulmonary disease, newly established on long-acting mono- or combination therapy. Int J Chron Obstruct Pulmon Dis. 2017;12:1825-1836.

6. Gruffydd-Jones K, Brusselle G, Jones R, et al. Changes in initial COPD treatment choice over time and factors influencing prescribing decisions in UK primary care: in UK primary care: a real-world, retrospective, observational. NPJ Prim Care Respir Med. 2016;26:16002.

7. Chalmers JD, Tebboth A, Gayle A, Ternouth A, Ramscar N. Determinants of initial inhaled corticosteroid use in patients with GOLD A/B COPD: a retrospective study of UK general practice. NPJ Prim Care Respir Med. 2017;27(1):43.

8. Ding B, Small M. Treatment trends in patients with asthma-COPD overlap syndrome in a COPD cohort: findings from a real-world survey. Int J Chron Obstruct Pulmon Dis. 2017;12:1753-1763.

9. Souliotis K, Kani C, Papageorgiou M, Lionis D, Gourgoulianis K. Using big data to assess prescribing patterns in Greece: the case of chronic obstructive pulmonary disease. PLoS One. 2016;11(5):e0154960.

10. Roman-Rodriguez M, van Boven JF, Vargas F, et al. Factors associated with inhaled corticosteroids prescription in primary care patients with COPD: a cross-sectional study in the Balearic Islands (Spain). Eur J Gen Pract. 2016;22(4):232-239.

11. Haycock C, Schandl A. A new tool for quality: the internal audit. Nurs Adm Q. 2017;41(4):321-327.

12. Ruparel M, Lopez-Campos JL, Castro-Acosta A, Hartl S, PozoRodriguez F, Roberts CM. Understanding variation in length of hospital stay for COPD exacerbation: European COPD audit. ERJ Open Res. 2016;2(1):pii 00034-2015.

13. Spruit MA, Pitta F, Garvey C, et al; ERS Rehabilitation and Chronic Care, and Physiotherapists Scientific Groups, American Association of Cardiovascular and Pulmonary Rehabilitation, ATS Pulmonary Rehabilitation Assembly and the ERS COPD Audit Team. Differences in content and organisational aspects of pulmonary rehabilitation programmes. Eur Respir J. 2014;43(5):1326-1337.
14. Roberts CM, Lopez-Campos JL, Pozo-Rodriguez F, Hartl S; European COPD Audit Team. European hospital adherence to GOLD recommendations for chronic obstructive pulmonary disease (COPD) exacerbation admissions. Thorax. 2013;68(12):1169-1171.

15. Lopez-Campos JL, Abad Arranz M, Calero Acuna C, et al. Clinical audits in outpatient clinics for chronic obstructive pulmonary disease: methodological considerations and workflow. PLoS One. 2015; 10(11):e0141856.

16. Lopez-Campos JL, Abad Arranz M, Calero Acuna C, et al. Determinants for changing the treatment of COPD: a regression analysis from a clinical audit. Int J Chron Obstruct Pulmon Dis. 2016;11:1171-1178.

17. Calle Rubio M, Alcazar Navarrete B, Soriano JB, et al. Clinical audit of COPD in outpatient respiratory clinics in Spain: the EPOCONSUL study. Int J Chron Obstruct Pulmon Dis. 2017;12:417-426.

18. Dahl R, Jadayel D, Alagappan VK, Chen H, Banerji D. Efficacy and safety of QVA149 compared to the concurrent administration of its monocomponents indacaterol and glycopyrronium: the BEACON study. Int J Chron Obstruct Pulmon Dis. 2013;8:501-508.

19. Hagedorn C, Kassner F, Banik N, Ntampakas P, Fielder K. Influence of salmeterol/fluticasone via single versus separate inhalers on exacerbations in severe/very severe COPD. Respir Med. 2013;107(4): 542-549.

20. Vestbo J, Papi A, Corradi M, et al. Single inhaler extrafine triple therapy versus long-acting muscarinic antagonist therapy for chronic obstructive pulmonary disease (TRINITY): a double-blind, parallel group, randomised controlled trial. Lancet. 2017;389(10082):1919-1929.

21. Bremner PR, Birk R, Brealey N, Ismaila AS, Zhu CQ, Lipson DA. Single-inhaler fluticasone furoate/umeclidinium/vilanterol versus fluticasone furoate/vilanterol plus umeclidinium using two inhalers for chronic obstructive pulmonary disease: a randomized non-inferiority study. Respir Res. 2018;19(1):19.

22. Miravitlles M, Soler-Cataluna JJ, Calle M, et al. Spanish COPD guidelines (GesEPOC): pharmacological treatment of stable COPD. Spanish society of pulmonology and thoracic surgery. Arch Bronconeumol. 2012;48(7):247-257.

23. Soriano JB, Lamprecht B, Ramirez AS, et al. Mortality prediction in chronic obstructive pulmonary disease comparing the GOLD 2007 and 2011 staging systems: a pooled analysis of individual patient data. Lancet Respir Med. 2015;3(6):443-450.

24. Calabro GE, De Waure C, Mogini V, et al. [Clinical audit as a quality improvement tool in the emergency setting. A systematic review of the literature]. Ig Sanita Pubbl. 2016;72(5):443-479.

25. Lopez-Campos JL, Asensio-Cruz MI, Castro-Acosta A, Calero C, Pozo-Rodriguez F; AUDIPOC and the European COPD Audit Studies. Results from an audit feedback strategy for chronic obstructive pulmonary disease in-hospital care: a joint analysis from the AUDIPOC and European COPD audit studies. PLoS One. 2014;9(10):e110394.

26. Stephenson M, McArthur A, Giles K, Lockwood C, Aromataris E, Pearson A. Prevention of falls in acute hospital settings: a multi-site audit and best practice implementation project. Int J Qual Health Care. 2016;28(1):92-98.

27. Gottlieb V, Lyngso AM, Saebye D, Frolich A, Backer V. The use of COPD maintenance therapy following spirometry in general practice. Eur Clin Respir J. Epub 2016 Jun 22.

28. Diette GB, Dalal AA, D'Souza AO, Lunacsek OE, Nagar SP. Treatment patterns of chronic obstructive pulmonary disease in employed adults in the United States. Int J Chron Obstruct Pulmon Dis. 2015;10: 415-422.

29. Brusselle G, Price D, Gruffydd-Jones K, et al. The inevitable drift to triple therapy in COPD: an analysis of prescribing pathways in the UK. Int J Chron Obstruct Pulmon Dis. 2015;10:2207-2217.

30. Price D, West D, Brusselle G, et al. Management of COPD in the UK primary-care setting: an analysis of real-life prescribing patterns. Int $J$ Chron Obstruct Pulmon Dis. 2014;9:889-904.

31. Falk J, Dik N, Bugden S. An evaluation of early medication use for COPD: a population-based cohort study. Int J Chron Obstruct Pulmon Dis. 2016;11:3101-3108. 
32. Lizano-Diez I, Modamio P, Lopez-Calahorra P, et al. Evaluation of electronic prescription implementation in polymedicated users of Catalonia, Spain: a population-based longitudinal study. BMJ Open. 2014;4(11):e006177.
33. Magnussen H, Watz H, Kirsten A, et al. Stepwise withdrawal of inhaled corticosteroids in COPD patients receiving dual bronchodilation: WISDOM study design and rationale. Respir Med. 2014;108(4): 593-599.

\section{Publish your work in this journal}

The International Journal of COPD is an international, peer-reviewed journal of therapeutics and pharmacology focusing on concise rapid reporting of clinical studies and reviews in COPD. Special focus is given to the pathophysiological processes underlying the disease, intervention programs, patient focused education, and self management protocols.
This journal is indexed on PubMed Central, MedLine and CAS. The manuscript management system is completely online and includes a very quick and fair peer-review system, which is all easy to use. Visit http://www.dovepress.com/testimonials.php to read real quotes from published authors. 